\title{
A case-crossover study to investigate the effects of atmospheric particulate matter concentrations, season and air temperature on accident and emergency presentations for cardiovascular events
}

Paolo Contiero ( $\sim$ paolo.contiero@istitutotumori.mi.it)

Fondazione IRCCS Istituto Nazionale dei Tumori https://orcid.org/0000-0001-6760-3605

Roberto Boffi

Fondazione IRCCS Istituto Nazionale dei Tumori

Giovanna Tagliabue

Fondazione IRCCS Istituto Nazionale dei Tumori

Alessandra Scaburri

Fondazione IRCCS Istituto Nazionale dei Tumori

Andrea Tittarelli

Fondazione IRCCS Istituto Nazionale dei Tumori

Martina Bertoldi

Fondazione IRCCS Istituto Nazionale dei Tumori

Alessandro Borgini

Fondazione IRCCS Istituto Nazionale dei Tumori

Immacolata Favia

Fondazione IRCCS Istituto Nazionale dei Tumori

Ario Alberto Ruprecht

Fondazione IRCCS Istituto Nazionale dei Tumori

Alfonso Maiorino

Istituto Clinico Humanitas

Antonio Voza

Istituto Clinico Humanitas

Marta Ripoll Pons

Istituto Clinico Humanitas

Alessandro Cau

Fondazione IRCCS Istituto Nazionale dei Tumori

Cinzia De Marco

Fondazione IRCCS Istituto Nazionale dei Tumori

Flavio Allegri

Fondazione IRCCS Istituto Nazionale dei Tumori 
Claudio Tresoldi

Universita degli Studi di Milano Facolta di Medicina e Chirurgia

Michele Ciccarelli

Istituto Clinico Humanitas

\section{Research article}

Keywords: particulate matter, atmospheric temperature, season, cardiovascular disease, climate change, accident and emergency, cancer, pollution, case-crossover study

Posted Date: July 17th, 2019

DOI: https://doi.org/10.21203/rs.2.11272/v1

License: (c) (i) This work is licensed under a Creative Commons Attribution 4.0 International License. Read Full License

Version of Record: A version of this preprint was published at International Journal of Environmental Research and Public Health on November 21st, 2019. See the published version at https://doi.org/10.3390/ijerph16234627. 


\section{Abstract}

ABSTRACT Background: Atmospheric particulate matter (PM) has multiple adverse effects on human health; high temperatures are also associated with adverse health outcomes; and the frequency of cardiovascular events (CVEs) varies with season. We investigated a hypothesized increase in PM-related accident and emergency (A\&E) presentations for CVE with temperature, season, days of high influenza incidence, and in persons with a cancer diagnosis. Methods: This was a time-stratified case-crossover study in which patients served as their own controls on days without A\&E presentation. Outcomes were associations of A\&E presentation for CVE with atmospheric PM $\leq 10 \mu \mathrm{m}$ (PM10), season, air temperature and influenza incidence. PM10 in municipality of residence (exposure variable) were estimated by modelling data from local monitoring stations. Conditional logistic regression models estimated odds ratios (OR) with $95 \%$ confidence intervals $(\mathrm{Cl})$ for presentations in relation to supposed influencers, adjusting for confounders. Separate analyses were performed on persons with a cancer diagnosis. Study participants were all who presented at the A\&E of a large hospital near Milan, Italy, for a CVE (ICD-9: 390459) from 1st January 2014 to 31st December 2015. Results: There were 1349 A\&E presentations for CVE in 2014-2015 and 5390 control days. Risk of A\&E presentation was significantly increased (OR 1.34, 95\% Cl 1.05-1.71) when PM10 was high (as mean PM10 on day of presentation, and 1 and 2 days before [lags 0 2]) on hot days and (for lag 0 ) in autumn (OR 1.23, 95\% Cl 1.09-1.37) and winter (OR 1.18, 95\% Cl 1.011.38). Risks were also significantly increased when PM10 was on lag 1 , in people with a cancer diagnosis in the spring and summer months $(1.88,95 \% \mathrm{Cl} 1.05-3.37)$, and on days (lags $0-2)$ of high influenza incidence (OR 2.34, 95\% Cl 1.01-5.43). Conclusions: Greater risk of A\&E presentation for CVE in periods of high PM10 and high temperature suggests that "safe" thresholds for PM10 should be temperature dependent and that the adverse effects of PM10 will increase as temperatures increase due to climate change.

\section{Background}

Air pollution is a major public health problem. The Global Burden of Diseases, Injuries, and Risk Factors Study [1] identified fine $(\leq 2.5 \mu \mathrm{m})$ atmospheric particulate matter (PM2.5) as responsible for 4.2 million deaths worldwide in 2015. Both $\mathrm{PM} \leq 10 \mu \mathrm{m}\left(\mathrm{PM}_{10}\right)$ and $\mathrm{PM} 2.5$ are known to have multiple adverse effects on human health [2,3], and are classified by the WHO and International Agency for Research on Cancer (IARC) as group 1 carcinogens (carcinogenic to humans) [4]. PM is emitted/formed by natural and anthropogenic processes. In industrial and urban areas PM is mainly anthropogenic [5].

In 2015 there were an estimated 420 million cases of cardiovascular disease (CVD) worldwide, and around 18 million deaths [6]. Extensive epidemiological and toxicological data demonstrate that particulate air pollution is associated with the development of CVD [7]. Short-term exposure can trigger acute events, while long-term exposure increases risk of a cardiovascular event (CVE) and can reduce life expectancy [7].

Associations between air temperature and CVEs and mortality have also been documented [8]. High air temperature has been associated with a worsened impact of $\mathrm{PM}_{10}$ on CVD outcomes including mortality 
$[9,10,11]$.

A 2017 review [12], noted that CVD-related hospitalizations and mortality were linked to cold snaps in winter, heat waves in summer, and atmospheric pollution, but that the effect of season was complex.

CVEs can be investigated by accessing health databases such as hospital admissions/discharges. Accident and emergency (A\&E) databases are of particular interest however because they archive presentations for a broader range of CVEs than hospital discharges.

To our knowledge no studies have investigated the effects of air temperature and season on the relation between $\mathrm{PM}_{10}$ and $\mathrm{A \& E}$ presentations for CVEs. In the present study we used a case-crossover approach to address this issue, investigating presentations for CVEs at the A\&E unit of Humanitas Hospital, Rozzano, near Milan, in the plain of the river Po.

The plain of the Po is a densely-populated area of 46,000 square kilometres, enclosed by mountains to the north, west and south. The mountains inhibit air circulation, and extended periods of air stasis contribute to some of the highest levels of air pollution in the world $[13,14]$.

The Mediterranean region, within which the Po Valley is situated, was considered highly vulnerable to climate change in the 5th (2014) Assessment Report of the Intergovernmental Panel on Climate Change [15] and temperatures in the region are projected to increase in coming years [16].

\section{Materials And Methods}

\section{Participants}

A\&E presentations from 1st January 2014 to 31 st December 2015 were accessed from the Humanitas A\&E database. Date of presentation, date of birth, sex, diagnosis, municipality of residence, and patient social security number were extracted. Only descriptive diagnoses were available - of which there could be several (those associated with the presentation and those for concomitant diseases, including cancer). From the descriptive diagnoses, presentations with a CVE were identified by project staff, and transformed into ICD-9 codes (390-459). Presentations were linked, via social security number, with the Region of Lombardy Social Security List to ascertain vital status, and, where pertinent, date of death. Extracted data were managed in a study database with safeguards in place to prevent unauthorized access and respect patient privacy. The A\&E presentations selected for study had a CVE and a municipality of residence within $20 \mathrm{~km}$ of Humanitas hospital. The $20 \mathrm{~km}$ cut-off was adopted as it is known that residences distant from the hospital are more likely to be incorrect so that misclassification of exposure is more likely.

\section{Exposure assessment}

The Lombardy Environmental Protection Agency (ARPA) measures $\mathrm{PM}_{10}$ at a series of monitoring stations in the Region of Lombardy. Using a model developed in house, ARPA uses monitoring station data to produce estimates of mean daily $\mathrm{PM}_{10}$ for each municipality within the Region [17], taking account of 
emissions from local pollution sources, daily meteorological data, and orography. The $\mathrm{PM}_{10}$ exposure of each participant was considered to be that of their municipality of residence.

The air temperature and humidity to be assigned (to each participant) on days of presentation and nonpresentation were obtained from the ARPA monitoring station nearest the municipality of residence [18]. Mean apparent temperature in degrees Celsius was assigned. Apparent temperature accounts for relative humidity effects and was estimated using the weather metrics procedure of the $\mathrm{R}$ statistical package [19].

\section{Study design and statistical analysis}

To determine risk of $A \& E$ presentation for a CVE in relation to mean daily $\mathrm{PM}_{10}$ a bidirectional timestratified case-crossover design was used. Cases were persons presenting at the A\&E for a CVE; controls were the same persons evaluated (for $\mathrm{PM}_{10}$, etc.) on days when they did not present. Control days were matched to case days by day of week such that control days could be $7,14,21$, or 28 days before or after the case day. Up to 4 control days per case were used.

$\mathrm{PM}_{10}$ exposure for each case and control was defined in 3 ways as follows: $\mathrm{PM}_{10}$ on the day of presentation (lag 0$), \mathrm{PM}_{10}$ on the day before (lag 1), $\mathrm{PM}_{10}$ two days before (lag 2).

Conditional logistic regression modelling was used to estimate odd ratios (ORs) for A\&E presentation for a $\mathrm{CVE}$, compared to non-presentation, in relation to $\mathrm{PM}_{10}$. $\mathrm{A}$ basic model assessed the effect of $\mathrm{PM}_{10}$ on $\mathrm{CVE}$ presentations considering various confounders. Three additional models were run with interactions for season, temperature and influenza incidence added successively, thus examining the effect on presentations of $\mathrm{PM}_{10}$ and season; $\mathrm{PM}_{10}$, season, and temperature; and $\mathrm{PM}_{10}$, season, temperature, and influenza incidence.

The basic logistic model was:

logit $\{Y=1 \mid X\}=\beta_{0}+\beta_{1} P M_{10}+\beta_{2}$ flu $+\beta_{3}$ holiday $+\beta_{4}$ pop_dec $+\beta_{5}$ app_temp $+\beta_{6}$ ozone $+\beta_{7} P_{10}$ * sex $+\beta_{7}$ $\mathrm{PM}_{10}$ * age

Where $\mathrm{Y}$ is the binary response variable for $\mathrm{A} \& \mathrm{E}$ presentation that takes values of 1 or 0 , the $\mathrm{Xs}$ are covariates, and the $\beta$ s regression coefficients. $\mathrm{PM}_{10}$ was considered as a linear variable, and ORs were estimated for $10 \mu \mathrm{g} / \mathrm{m} 3$ increments of $\mathrm{PM}_{10}$. Dummy variables for influenza incidence (flu), day of holiday (holiday), and population decrease due to summer holidays (pop_dec) were added. Days of influenza incidence were identified by consulting Influnet, the Italian national surveillance system $[20,21]$ and categorised into four levels, from no influenza days to high influenza days.

A term for apparent temperature (app_temp) was also included, categorized as: high ( $>80$ th percentile), medium (20th-80th percentiles), and low (<20th percentile). A linear term for ozone levels (obtained from ARPA monitoring stations) and interaction terms of $\mathrm{PM}_{10}$ with sex and age were also added because of their supposed roles as confounders or modifiers. 
Separate basic models were run for $\mathrm{PM}_{10}$ at lags $0,1,2$ and $0-2$ (the latter as average $\mathrm{PM}_{10}$ at lags 0,1 and 2). The linearity of the relationship between $A \& E$ presentation and $P M_{10}$ was assessed by adding a restricted cubic spline term to model $\mathrm{PM}_{10}$ and evaluating the difference between models with and without the restricted cubic spline, using the likelihood ratio test [22].

A product term, $\mathrm{PM}_{10}$ *season, was added to the basic model to test whether season modified the association between $\mathrm{PM}_{10}$ and $\mathrm{CVE}$ presentation and the likelihood ratio test used to compare models with and without the $\mathrm{PM}_{10}$ *season interaction term. Seasons were defined as: March 21-June 20 (spring); June 21-September 22 (summer); September 23-December 20 (autumn); and December 21-March 20 (winter). Separate models were run at lags $0,1,2$ and $0-2$.

A product term, $\mathrm{PM}_{10}$ *apparent_temperature, was added to the basic plus season model to test whether apparent temperature modified the association between $\mathrm{PM}_{10}$ and CVE presentation, the likelihood ratio test was used to compare models with and without the $\mathrm{PM}_{10}$ and apparent temperature interaction term. Separate models were run at lags $0,1,2$ and $0-2$.

Finally the product term $\mathrm{PM}_{10}{ }^{*}$ influenza was added to the basic plus season plus apparent temperature model, and the likelihood ratio test used to test for an interaction between $\mathrm{PM}_{10}$ and influenza in relation to A\&E presentation.

Separate models (basic and seasonal models) that included only patients (A\&E presentations) with a diagnosis of cancer were run. Because of the small number of cancer patients, only two seasons were considered: cold season (autumn plus winter) and warm season (spring plus summer).

The analyses were performed using the R statistical package [19]. Differences were considered significant for $P<0.05$.

\section{Results}

A total of 1349 A\&E presentations for CVE were identified in the 2014-15 study period; 5390 control days were selected for comparison (thus most presentation dates for most participants had four control dates). Table 1 shows the distributions of presentations by age and sex, together with the distributions of $\mathrm{PM}_{10}$ and apparent temperature, all by season. A total of 168 presenters had been previously diagnosed with cancer (as determined from the A\&E database). Table 2 shows ORs of A\&E presentation for CVE in relation to atmospheric $\mathrm{PM}_{10}$. The third column of table 2 shows results for the basic models: $\mathrm{PM}_{10}$ was never significant in any model or any lag.

The fourth column of Table 2 shows results when the $\mathrm{PM}_{10}{ }^{*}$ season interaction was added to the basic model. With spring as reference, ORs in autumn for A\&E presentations for CVEs were $1.21(95 \% \mathrm{Cl} 1.09$ 1.35) per $10 \mu \mathrm{g} / \mathrm{m} 3$ increment in $\mathrm{PM}_{10}$ for lag $0 ; 1.14$ (95\% Cl 1.02-1.27) for lag 1, 1.05 (95\% $\left.\mathrm{Cl} 0.94-1.17\right)$ for lag 2, and $1.17(95 \% \mathrm{Cl} 1.04-1.33)$ for lags $0-2$. ORs for A\&E presentations in winter (reference spring) 
were $1.13(95 \% \mathrm{Cl} 1.02-1.26)$ for lag $0 ; 1.15(95 \% \mathrm{Cl} 1.04-1.28)$ for lag $1 ; 1.06(95 \% \mathrm{Cl} 0.96-1.18)$ for lag 2 ; and $1.16(95 \% \mathrm{Cl} 1.03-1.31)$ for lags $0-2$. ORs for summer were never significant for any lag.

The fifth column of table 2 shows results after adding the interaction between $\mathrm{PM}_{10}$ and apparent temperature to the model of the fourth column. In this model ORs per season changed slightly compared to the previous model, but significance never changed. When it was hot (reference moderate temperature), ORs of presentation were $1.20(95 \% \mathrm{Cl} 0.98-1.48)$ per $10 \mu \mathrm{g} / \mathrm{m} 3 \mathrm{PM}_{10}$ increment for lag $0 ; 1.27(95 \% \mathrm{Cl} 1.03-$ 1.56) for lag $1 ; 1.23(95 \% \mathrm{Cl} 1.00-1.51)$ for lag 2 ; and $1.34(95 \% \mathrm{Cl} 1.05-1.71)$ for lags $0-2$. ORs for were never significant when it was cold.

The sixth column of table 2 shows results after adding an interaction term for $\mathrm{PM}_{10}$ and influenza to the model of the fifth column. In this model, ORs for season changed slightly compared to the previous model but none of the significant ORs became non-significant and none of the non-significant ORs became significant. On days when influenza notifications were high, (reference days with no influenza) ORs per 10 $\mu \mathrm{g} / \mathrm{m} 3 \mathrm{PM}_{10}$ increment were $1.17(95 \% \mathrm{Cl} 0.75-1.84)$ for lag $0 ; 1.34(95 \% \mathrm{Cl} 0.80-2.25)$ for lag $1 ; 1.34(95 \% \mathrm{Cl}$ 0.84-2.15) for lag 2; and $2.34(95 \% \mathrm{Cl} 1.01-5.43)$ for lags $0-2$. After inserting the interaction term between $\mathrm{PM}_{10}$ and influenza incidence, the interaction between $\mathrm{PM}_{10}$ and winter became non-significant for lags 0 2.

Use of restricted cubic spline $\mathrm{PM}_{10}$ modelling and the likelihood ratio test provided no reason to reject the null hypothesis of a linear association between $A \& E$ presentation and $\mathrm{PM}_{10}$ levels. Similar testing provided no reason to reject the null hypothesis of a linear association between $A \& E$ presentation and $\mathrm{PM}_{10}$ levels on days of high influenza incidence.

For presenters with a previous cancer diagnosis, the basic model provided ORs of $1.03(95 \% \mathrm{Cl} 0.81-1.32)$ for lag $0 ; 1.08(95 \% \mathrm{Cl} 0.81-1.43)$ for lag $1 ; 1.21(95 \% \mathrm{Cl} 0.90-1.63)$ for lag 2 ; and $1.13(95 \% \mathrm{Cl} 0.83-1.54)$ for lags 0-2. For presenters with a previous cancer diagnosis, ORs for warm season presentation were 1.64 (95\% Cl 0.89-3.01) for lag $0 ; 1.88(95 \% \mathrm{Cl} 1.05-3.37)$ for lag $1 ; 1.32(95 \% \mathrm{Cl} 0.80-2.19)$ for lag 2 ; and 1.13 $(95 \% \mathrm{Cl} 0.83-1.54)$ for lags $0-2$. For presenters with a previous cancer diagnosis, ORs for cold season presentation were $0.92(95 \% \mathrm{Cl} 0.69-1.25)$ for lag $0 ; 0.84(95 \% \mathrm{Cl} 0.57-1.23)$ for lag $1 ; 1.15(95 \% \mathrm{Cl} 0.80-1.67)$ for lag 2; and $0.93(95 \% \mathrm{Cl} 0.62-1.40)$ for lags 0-2 (data not presented in tables).

ARPA modelling estimated that $\mathrm{PM}_{10}$ levels exceeded the $50 \mu \mathrm{g} / \mathrm{m} 3$ "safe" threshold recommended by the WHO [23] and Italian legislation for only $3.8 \%$ of days (in some municipalities) during the warm periods of 2014-2015.

\section{Discussion}

We have found that increasing atmospheric $\mathrm{PM}_{10}$ (continuous variable) was associated with greater risk of A\&E presentation for a CVE during autumn and winter than spring, and also when temperatures were high (reference moderate temperature) irrespective of season. $\mathrm{PM}_{10}$ was not associated with $\mathrm{A} \& \mathrm{E}$ 
presentation for a CVE in summer or on cold days. Thus our analyses distinguished the effect of season from the effect of temperature. We also found that risk of presentation increased significantly with increasing $\mathrm{PM}_{10}$ during days of high influenza incidence, which occurred exclusively in the cold winter months. Furthermore, for persons with a previous cancer diagnosis - who are to be considered frail according to standard definitions [24] - risk of A\&E presentation for CVE increased with increasing $\mathrm{PM}_{10}$ during spring plus summer, but not during autumn plus winter.

To our knowledge no previous study has reported the risk of A\&E presentation for CVEs in relation to interactions between $\mathrm{PM}_{10}$ and season and interactions between $\mathrm{PM}_{10}$ and temperature at the same time. However this important novelty renders comparisons with the findings of other studies difficult. In fact few previous studies have investigated the influence of temperature on PM-related A\&E presentations for CVEs. A 2017 study conducted in Beijing [10] found that CVEs associated with $10 \mathrm{mg} / \mathrm{m} 3$ increments of $\mathrm{PM}_{10}$ increased by $0.14 \%$ when air temperature was $\geq 28^{\circ} \mathrm{C}$. A study conducted in Brisbane [9] found that high $\mathrm{PM}_{10}$ was associated with more adverse health effects, including cardiovascular emergency visits, on warm days than cold days, for lags up to 2 days. Our findings are fully consistent with these findings. They are also consistent with the findings of a 2018 study on a European urban area [25] that investigated total natural and cardiovascular mortality in relation to air temperature and particle number concentration, $\mathrm{PM} 2.5, \mathrm{PM}_{10}$ and ozone. This study found that on high air temperature days ( $>75$ th percentile), a 10 $\mu \mathrm{g} / \mathrm{m} 3$ increase in $\mathrm{PM}_{10}$ was associated with a $1.61 \%$ increase in cardiovascular mortality, which was significantly higher than on low temperature ( $<25$ th percentile) days. Furthermore, on high air pollution days (>50th percentile), both hot and cold related mortality risks increased.

The effect of high temperature on $\mathrm{PM}_{10}$-related $A \& E$ presentations may have various causes. One could be that $\mathrm{PM}_{10}$ composition varies with season. For example, levels of chromium and mercury in $\mathrm{PM}_{10}$ at a roadside site in Beijing were found to be higher in summer than winter [26]. Furthermore a 2013 study [27] exposed human macrophage-like cells to summer and winter $\mathrm{PM}_{10}$ from the Milan atmosphere and measured the release of the proinflammatory interleukin $1 \beta$ (IL1 $\beta)$. IL1 $\beta$ release increased in a dosedependent manner on exposure to summer $\mathrm{PM}_{10}$ but not to winter $\mathrm{PM}_{10}$. The authors concluded that Milan summer $\mathrm{PM}_{10}$ contains substances that promote the activation of membrane Toll-like receptors and the NLPR3 inflammasome, to stimulate IL1 $\beta$ release.

Our findings are compatible with of those of the above studies $[25,26,27]$ in that all found risk increases in summer. Furthermore the Milan [27] data suggest that high summer $\mathrm{PM}_{10}$ stimulates inflammation which could explain, at least in part, why $\mathrm{PM}_{10}$-related risk of A\&E presentation for CVE increases on hot days. We also found significantly increased $\mathrm{PM}_{10}$-related risks in winter and autumn (reference spring), not observed in the Milan study [27], suggesting that a different (non-IL1 $\beta$-related) mechanism was responsible for this increase.

High temperatures exacerbate the toxic effects of many environmental toxins by various mechanisms [11]. $\mathrm{PM}_{10}$, and its toxic components, enter the body via the skin and respiratory surfaces. When air temperature 
is high peripheral vasodilatation increases resulting in higher skin temperature. Respiration is also moderately increased to increase heat dissipation by evaporation. These two temperature responses enhance the entry of PM into the body.

Toxin inhalation may result in pulmonary inflammation and oxidative stress, leading to the release of proinflammatory cytokines giving rise to systemic inflammation. People typically spend more time outdoors and open their windows more during the summer months, thereby increasing their exposure PM and other atmospheric pollutants [28].

Our finding that cold days had no influence on $\mathrm{PM}_{10}$-related risk of presentation, while risk was increased in the winter and autumn is intriguing

and suggests an influence of seasonal risk factors unrelated to temperature. The review of Steward et al12 highlighted the influence of seasonal behavioural changes (e.g. changes in diet and physical activity) on CVE risk, possibly mediated by a behavioural change effect on PM-induced inflammation.

It is noteworthy that in our study A\&E presentations for CVEs increased significantly with increasing $\mathrm{PM}_{10}$ during days of high influenza incidence. Influenza has been implicated as a contributory factor to acute myocardial infarction [29, 30]. The increased levels of inflammatory cytokines, in particular IL18 [31], that occur as a response to viral influenza may increase the risk myocardial infarction. Increased inflammatory cytokine levels due to high $\mathrm{PM}_{10}$ may further increase the risk of infarction.

People with a previous cancer diagnosis are frail [24] and known to be at increased risk of hospital admission for several causes not directly related to cancer [32]. Frailty is a state of heightened vulnerability to stressors [24]; in our case stressors would include cancer, treatment-induced cardiotoxicity, PM and air temperature [33]. In fact CVD is the second leading cause of morbidity and mortality in cancer survivors mainly because of treatment-induced cardio toxicity [32]. $\mathrm{PM}_{10}$ also influences cardiovascular mortality [7, 25] and cancer prognosis [34]. We found that ORs for A\&E presentations for CVE were higher for cancer patients than other categories, highlighting cancer patient susceptibility to high $\mathrm{PM}_{10}$.

We assessed risks of presentation in relation to lag between high $\mathrm{PM}_{10}$ and day of presentation. In winter and autumn, the effect of high $\mathrm{PM}_{10}$ on risk of presentation was numerically greatest on the day of exposure (lag 0 ) to decline thereafter. By contrast the effects of hot day and high flu incidence on $\mathrm{PM}_{10^{-}}$ related presentation seemed to be cumulative since ORs were greatest for lag 0-2. This variation in risk of $\mathrm{PM}_{10}$-related CVE presentation with lag suggests various mechanisms are involved.

Our study has limitations. First, the study population is fairly small. Second, each person's PM 10 exposure was considered to be the mean daily exposure estimated for the entire municipality of residence, since only municipality-level $\mathrm{PM}_{10}$ estimates were available. However misclassifications of exposure due to municipality-level estimation are likely to weaken associations overall rather than introduce bias. 
The case-crossover design is a study strength since confounding due to quasi periodic fluctuations in pollution levels over a week were controlled for by day-of-the-week matching, and time-invariant confounders like age, sex and smoking were controlled for automatically. The persons presenting at the A\&E with CVEs were unselected so our sample is likely to be representative of the general population. Furthermore the $\mathrm{PM}_{10}$ measurement method and the diagnosis assignments (ICD 9 codes) were standard. Thus we expect the generalizability of our findings to be good.

\section{Conclusions}

This study provides evidence that increasing temperature exacerbates at least one of the documented adverse effects of atmospheric $\mathrm{PM}_{10}$ on human health. However European and Italian legislation indicating "safe" thresholds for atmospheric $\mathrm{PM}_{10}$ levels does not take account of this exacerbating effect. Our data suggest - at the very least - that these thresholds should be lower during periods of high air temperature. Measures to ensure that thresholds are not exceeded are also required. As global temperatures increase $[15,16]$ the adverse health effects of atmospheric $\mathrm{PM}_{10}$ will probably worsen, irrespective of whether atmospheric $\mathrm{PM}_{10}$ levels are reduced.

\section{List Of Abbreviations}

Lag 0: same day as A\&E presentation

Lag 1: day before A\&E presentation

Lag 2: two days before A\&E presentation

Lag 0-2: average of $\mathrm{PM}_{10}$ levels from lag 0 to lag 2

PM: atmospheric particulate matter

CVE: cardiovascular event

A\&E: accident and emergency

Cl: confidence interval

OR: odds ratio

ARPA: Lombardy Environmental Protection Agency

\section{Declarations}

Ethical approval 
The study design was approved from the ethical committee of the Fondazione IRCCS Istituto Nazionale dei Tumori di Milano in November 282018.

Consent for publication

Not applicable

Availability of data and materials

The datasets used and/or analysed during this study are not available because of the privacy legislation.

Competing interests

All authors declare that they have no competing interests.

Funding

This research received no specific grant from any funding agency in the public, commercial or not-for-profit sectors.

Authors' contributions

PC contributed to study conception, planning and interpretation; he designed the study, performed the statistical analyses and wrote the first draft.

MC and RB contributed to study conception, planning and interpretation.

GT contributed to study conception and planning, and coordinated the clinical epidemiology sections of the study.

$M C, A M, A V$ and MRP diagnosed cases presenting at the A\&E.

$A B, M B, A A R, A T$ and $C D M$ were responsible for assessing $\mathrm{PM}_{10}$ and other exposures.

AS, AT and MB developed and managed the information system to hold and manipulate study data and performed the descriptive statistics.

IF, AS and AC transformed the descriptive diagnoses of cases into ICD9 diagnoses.

CT was responsible for validation of influenza incidence data.

All authors have read and approved the final manuscript.

Acknowledgement

The authors thank Don Ward for help with the English and for critically reading the manuscript. 


\section{References}

1. Cohen AJ, Brauer M, Burnett R, Anderson HR, Frostad J, Estep K, et al. Estimates and 25-year trends of the global burden of disease attributable to ambient air pollution: an analysis of data from the Global Burden of Diseases Study 2015. Lancet 2017;389:1907-1918.

2. Barman SC, Kumar N, Singh R, Kisku GC, Khan AH, Kidwai MM, et al. Assessment of urban air pollution and it's probable health impact. J Environ Biol 2010;31:913-920.

3. IARC monographs: volume 109: Outdoor Air Pollution. http://monographs.iarc.fr/ENG/Monographs/vol109/mono109.pdf. Accessed 4th July2019.

4. IARC Scientific Publication No. 161: Air Pollution and Cancer.

http://www.iarc.fr/en/publications/books/sp161/AirPollutionandCancer161.pdf. Accessed 4th July2019.

5. Karagulian F, Belis CA, Dora CFC, Prüss-Ustün AM, Bonjour S, Adair-Rohani H, et al. Contributions to cities' ambient particulate matter (PM): A systematic review of local source contributions at global level. Atmospheric Environment 2015;120:475-483.

6. Roth GA, Johnson C, Abajobir A, Abd-Allah F, Abera SF, Abyu G, et al. Global, Regional, and National Burden of Cardiovascular Diseases for 10 Causes, 1990 to 2015. J Am Coll Cardiol 2017;70:1-25.

7. Vidale S, Campana C. Ambient air pollution and cardiovascular diseases: From bench to bedside. Eur J Prev Cardiol 2018;25:818-825.

8. Basu R. High ambient temperature and mortality: a review of epidemiologic studies from 2001 to 2008. Environ Health 2009;16:8-40.

9. Ren C, Tong S. Temperature modifies the health effects of particulate matter in Brisbane, Australia. Int J Biometeorol 2006;51:87-96.

10. Zhang Y, Wang S, Fan X, YeX. Temperature modulation of the health effects of particulate matter in Beijing, China. Environ Sci Pollut Res Int 2018;25:10857-10866.

11. Gordon CJ. Role of environmental stress in the physiological response to chemical toxicants. Environ Res 2003;92:1-7.

12. Stewart S, Keates AK, Redfern A, McMurray JJV. Seasonal variations in cardiovascular disease. Nature Reviews Cardiology 2017; 14:654-664.

13. Raaschou-Nielsen O, Andersen ZJ, Beelen R, Samoli E, Stafoggia M, Weinmayr G, et al. Air pollution and lung cancer incidence in 17 European cohorts: prospective analyses from the European Study of Cohorts for Air Pollution Effects (ESCAPE). Lancet Oncol 2013;14:813-822. 
14. Van Donkelaar A, Martin RV, Brauer M, Boys BL. Use of satellite observations for long-term exposure assessment of global concentrations of fine particulate matter. Environ Health Perspect 2015;123:135-143.

15. AR5 Climate Change 2014: Impacts, Adaptation, and Vulnerability. https://www.ipcc.ch/site/assets/uploads/2018/02/WGIIAR5-Chap23_FINAL.pdf. Accessed 4th July2019.

16. IPCC Intergovernmental Panel On Climate Change. http://www.ipcc.ch/ipccreports/tar/wg1/index.php? idp=49. Accessed 4th July2019.

17. ARPA LOMBARDIA. https://www.arpalombardia.it/Pages/Aria/qualita-aria.aspx. Accessed 4th July2019.

18. ARPA LOMBARDIA. https://www.arpalombardia.it/siti/arpalombardia/meteo/richiesta-datimisurati/Pagine/RichiestaDatiMisurati.aspx. Accessed 4th July2019.

19. R Development Core Team (2007), R: a language and environment for statistical computing. http://www.r-project.org.

20. Rizzo C, Bella A, Alfonsi V, Puzelli S, Palmieri AP, Chironna M et al. Influenza vaccine effectiveness in Italy: Age, subtype-specific and vaccine type estimates 2014/15 season. Vaccine 2016;34:3102-3108.

21. InfluNet, Rete Italiana Sorveglianza Influenza. ISS. https://old.iss.it/site/RMI/influnet/Default.aspx. Accessed 4th July2019.

22. Harrell FE. Regression Modeling Strategies: With Applications to Linear Models, Logistic and Ordinal Regression, and Survival Analysis. Second ed. New York: Springer, 2015.

23. WHO Air quality guidelines for particulate matter, ozone, nitrogen dioxide and sulfur dioxide. http://apps.who.int/iris/bitstream/handle/10665/69477/WHO_SDE_PHE_OEH_06.02_eng.pdf;sequence=1. Accessed 4th July2019.

24. Ethun CG, Bilen MA, Jani AB, Maithel SK, Ogan K, Master VA. Frailty and cancer: Implications for oncology surgery, medical oncology, and radiation oncology. CA Cancer J Clin 2017;67:362-377.

25. Chen K, Wolf K, Breitner S, Gasparrini A, Stafoggia M, Samoli E, et al. Two-way effect modifications of air pollution and air temperature on total natural and cardiovascular mortality in eight European urban areas. Environ Int 2018;116:186-196

26. Yan-Ju Liu, Ting-Ting Zhang, Qing-Yang Liu, Ren-Jian Zhang , Zhen-Quan Sun, Mei-Gen Zhang. Seasonal variation of Physical and Chemical Properties in TSP, PM 10 and PM2.5 at a Roadside Site in Beijing and Their Influence on Atmospheric Visibility. Aerosol and Air Quality Research 2014;14:954-969.

27. Bengalli R, Molteni $E$, Longhin E, Refsnes $M$, Camatini M, Gualtieri M. Release of IL-1 $\beta$ triggered by Milan summer $\mathrm{PM}_{10}$ : molecular pathways involved in the cytokine release. Biomed Res Int 2013;2013:158093. 
28. Meng X, Ma Y, Chen R, Zhou Z, Zhou Z, Chen B, Kan H. Size-fractionated particle number concentrations and daily mortality in a Chinese city. Environ Health Perspect 2013;121:1174-1178.

29. Nguyen JL, Yang W, Ito K, Matte TD, Shaman J, Kinney PL. Seasonal Influenza Infections and Cardiovascular Disease Mortality. JAMA Cardiol 2016;1:274-281.

30. Kwong JC, Schwartz KL, Campitelli MA, Chung H, Crowcroft NS, Karnauchow T. Acute Myocardial Infarction after Laboratory-Confirmed Influenza Infection. N Engl J Med 2018;378:345-353.

31. Kaplanski G. Interleukin-18: Biological properties and role in disease pathogenesis. Immunol Rev. 2018;281:138-153.

32. Lenneman CG, Sawyer DB. Cardio-Oncology: An Update on Cardiotoxicity of Cancer-Related Treatment. Circ Res 2016;118:1008-1020

33. Kimberly DA, Salice CJ. Understanding interactive effects of climate change and toxicants: importance of evolutionary processes. Integr Environ Assess Manag 2012;8:385-6.

34. Tagliabue G, Borgini A, Tittarelli A, van Donkelaar A, Martin RV, Bertoldi M, et al. Atmospheric fine particulate matter and breast cancer mortality: a population-based cohort study. BMJ Open 2016;6:e012580

\section{Tables}

Table 1. Patient characteristics, atmospheric $\mathrm{PM}_{10}$, apparent atmospheric temperature and influenza incidence by season 
Season

\begin{tabular}{|c|c|c|c|c|}
\hline & Spring & Summer & Autumn & Winter \\
\hline Distribution of A\&E presentations (\%) & 28.8 & 22.7 & 19.8 & 28.7 \\
\hline \multicolumn{5}{|l|}{ Age distribution (years) } \\
\hline First age quartile & $\geq 21$ to $<67$ & $\geq 21$ to $<63$ & $\geq 42$ to $<68$ & $\geq 39$ to $<71$ \\
\hline Second age quartile & $\geq 67$ to $<78$ & $\geq 63$ to $<76$ & $\geq 68$ to $<78$ & $\geq 71$ to $<80$ \\
\hline Third age quartile & $\geq 78$ to $<84$ & $\geq 76$ to $<83$ & $\geq 78$ to $<85$ & $\geq 80$ to $<86$ \\
\hline Fourth age quartile & $\geq 84$ to $\leq 99$ & $\geq 83$ to $\leq 100$ & $\geq 85$ to $\leq 95$ & $\geq 86$ to $\leq 99$ \\
\hline \multicolumn{5}{|l|}{$\operatorname{Sex}(\%)$} \\
\hline Male & 56.6 & 58.4 & 58.5 & 54.3 \\
\hline Female & 44.4 & 41.6 & 41.5 & 45.7 \\
\hline
\end{tabular}

$\mathrm{PM}_{10}\left(\mu \mathrm{g} / \mathrm{m}^{3}\right)$

\begin{tabular}{llll} 
First $\mathrm{PM}_{10}$ quartile & $\geq 7$ to $<17 \geq 7$ to $<17 \geq 15$ to $<28$ & $\geq 12$ to $<31$ \\
\hline Second $\mathrm{PM}_{10}$ quartile & $\geq 17$ to $<24 \geq 17$ to $<23 \geq 28$ to $<38 \geq 31$ to $<47$ \\
\hline Third $\mathrm{PM}_{10}$ quartile & $\geq 24$ to $<34 \geq 23$ to $<28 \geq 38$ to $<53 \geq 47$ to $<59$ \\
Fourth $\mathrm{PM}_{10}$ quartile & $\geq 34$ to $\leq 65 \geq 28$ to $\leq 44 \geq 53$ to $\leq 100 \geq 59$ to $\leq 143$
\end{tabular}

Apparent temperature $\left({ }^{\circ} \mathrm{C}\right)$

\begin{tabular}{lcccc}
\hline Low $(<$ 20th percentile) & $<13$ & $<20$ & $<10$ & $<3$ \\
\hline Medium (20th-80th percentile) & $\geq 13$ to $\leq 20$ & $\geq 20$ to $\leq 26$ & $\geq 10$ to $\leq 17$ & $\geq 3$ to $\leq 8$ \\
\hline High ( $>$ 80th percentile) & $>20$ & $>26$ & $>17$ & $>8$ \\
\hline Influenza incidence (as \% of days) & & 100 & 96 & 13 \\
\hline Absent & 95 & 0 & 4 & 39 \\
\hline Low & 5 & 0 & 0 & 43 \\
\hline Medium & 0 & 0 & 0 & 5 \\
\hline High & 0 & 17 & \\
\hline
\end{tabular}


Table 2. Odd ratios (OR) with 95\% confidence intervals (CI) for A\&E presentations for cardiovascular events in relation to $10 \mu \mathrm{g} / \mathrm{m}^{3} \mathrm{PM}_{10}$ increments, according to season, temperature and influenza incidence, by lag. 


\begin{tabular}{|c|c|c|c|c|c|}
\hline \multirow[t]{2}{*}{ Lag } & \multirow{2}{*}{$\begin{array}{c}\text { Model } \\
\text { variables }\end{array}$} & \multicolumn{4}{|c|}{ OR (95\%CI) } \\
\hline & & $\begin{array}{l}\text { Basic } \\
\text { model }\end{array}$ & $\begin{array}{l}\mathrm{PM}_{10}+\text { season } \\
\text { interaction }\end{array}$ & $\begin{array}{l}\mathrm{PM}_{10}+\text { season }+ \\
\text { temperature interaction }\end{array}$ & $\begin{array}{l}\mathrm{PM}_{10}+\text { season }+ \text { temperature + } \\
\text { influenza interaction }\end{array}$ \\
\hline \multicolumn{6}{|c|}{$\left(\mathrm{PM}_{10}\right)$} \\
\hline \multirow{29}{*}{$\begin{array}{l}\text { Lag } \\
0\end{array}$} & & $0.96(0.86-$ & $0.83(0.72-0.96)$ & $0.81(0.70-0.94)$ & $0.82(0.71-0.95)$ \\
\hline & PM 10 and season & & & & \\
\hline & interaction: & & & & \\
\hline & $\mathrm{PM}_{10}$ and & N/A & 1 (ref) & 1 (ref) & 1 (ref) \\
\hline & spring & & & & \\
\hline & $\mathrm{PM}_{10}$ and & N/A & $1.18(0.99-1.41)$ & $1.09(0.89-1.32)$ & $1.08(0.89-1.32)$ \\
\hline & summer & & & & \\
\hline & $\mathrm{PM}_{10}$ and & N/A & $1.14(1.02-1.27)$ & $1.16(1.04-1.30)$ & $1.17(1.04-1.31)$ \\
\hline & autumn & & & & \\
\hline & $\mathrm{PM}_{10}$ and & N/A & $1.15(1.04-1.28)$ & $1.16(1.03-1.31)$ & $1.16(1.00-1.36)$ \\
\hline & winter & & & & \\
\hline & $\mathrm{PM}_{10}$ and temper & ature & & & \\
\hline & interaction: & & & & \\
\hline & $\mathrm{PM}_{10}$ and & N/A & N/A & 1 (ref) & 1 (ref) \\
\hline & mod. temp. & & & & \\
\hline & $\mathrm{PM}_{10}$ and & N/A & N/A & $1.01(0.92-1.10)$ & $0.99(0.90-1.09)$ \\
\hline & cold temp. & & & & \\
\hline & $\mathrm{PM}_{10}$ and hot & N/A & N/A & $1.20(0.98-1.48)$ & $1.19(0.97-1.46)$ \\
\hline & temp. & & & & \\
\hline & $\mathrm{PM}_{10}$ and flu inci & dence & & & \\
\hline & interaction: & & & & \\
\hline & $\mathrm{PM}_{10}$ and no & N/A & N/A & N/A & 1 (ref) \\
\hline & flu & & & & \\
\hline & $\mathrm{PM}_{10}$ and low & N/A & N/A & N/A & $0.93(0.81-1.08)$ \\
\hline & flu & & & & \\
\hline & $\mathrm{PM}_{10}$ and & N/A & N/A & N/A & $0.99(0.84-1.16)$ \\
\hline & medium flu & & & & \\
\hline & $\mathrm{PM}_{10}$ and & N/A & N/A & N/A & $1.17(0.75-1.84)$ \\
\hline & high flu & & & & \\
\hline \multirow{16}{*}{$\begin{array}{l}\text { Lag } \\
1\end{array}$} & $\mathrm{PM}_{10}$ & $1.03(0.92-$ & $0.92(0.79-1.06)$ & $0.89(0.77-1.03)$ & $0.89(0.77-1.03)$ \\
\hline & & 1.16) & & & \\
\hline & \multicolumn{5}{|l|}{$\mathrm{PM}_{10}$ and season } \\
\hline & \multicolumn{5}{|l|}{ interaction: } \\
\hline & $\mathrm{PM}_{10}$ and & N/A & 1 (ref) & 1 (ref) & 1 (ref) \\
\hline & spring & & & & \\
\hline & $\mathrm{PM}_{10}$ and & N/A & $1.18(0.99-1.41)$ & $1.09(0.89-1.32)$ & $1.08(0.89-1.32)$ \\
\hline & summer & & & & \\
\hline & $\mathrm{PM}_{10}$ and & N/A & $1.14(1.02-1.27)$ & $1.16(1.04-1.30)$ & $1.17(1.04-1.31)$ \\
\hline & autumn & & & & \\
\hline & $\mathrm{PM}_{10}$ and & N/A & $1.15(1.04-1.28)$ & $1.16(1.03-1.31)$ & $1.16(1.00-1.36)$ \\
\hline & winter & & & & \\
\hline & \multicolumn{5}{|c|}{$\mathrm{PM}_{10}$ and temperature } \\
\hline & interaction: & & & & \\
\hline & $\mathrm{PM}_{10}$ and & N/A & N/A & 1 (ref) & 1 (ref) \\
\hline & mod. temp. & & & & \\
\hline
\end{tabular}




\begin{tabular}{|c|c|c|c|c|}
\hline $\begin{array}{l}\mathrm{PM}_{10} \text { and } \\
\text { cold temp. }\end{array}$ & N/A & N/A & $1.02(0.94-1.11)$ & $1.01(0.91-1.11)$ \\
\hline $\begin{array}{l}\mathrm{PM}_{10} \text { and hot } \\
\text { temp. }\end{array}$ & N/A & N/A & $1.27(1.03-1.56)$ & $1.27(1.03-1.56)$ \\
\hline \multicolumn{5}{|c|}{$\begin{array}{l}\mathrm{PM}_{10} \text { and flu incidence } \\
\text { interaction: }\end{array}$} \\
\hline $\begin{array}{l}\mathrm{PM}_{10} \text { and no } \\
\text { flu }\end{array}$ & N/A & N/A & N/A & 1 (ref) \\
\hline $\begin{array}{l}\mathrm{PM}_{10} \text { and low } \\
\text { flu }\end{array}$ & N/A & N/A & N/A & $0.98(0.85-1.13)$ \\
\hline $\begin{array}{l}\mathrm{PM}_{10} \text { and } \\
\text { medium flu }\end{array}$ & N/A & N/A & N/A & $1.02(0.87-1.20)$ \\
\hline $\begin{array}{l}\mathrm{PM}_{10} \text { and } \\
\text { high flu }\end{array}$ & N/A & N/A & N/A & $1.34(0.80-2.25)$ \\
\hline
\end{tabular}


$\mathrm{PM}_{10}$ and season interaction:

$\begin{array}{llccc}\mathrm{PM}_{10} \text { and spring } & \text { N/A } & 1 \text { (ref) } & 1 \text { (ref) } & 1 \text { (ref) } \\ \mathrm{PM}_{10} \text { and summer } & \text { N/A } & 1.02(0.86-1.21) & 0.95(0.78-1.14) & 0.95(0.79-1.16) \\ \mathrm{PM}_{10} \text { and autumn } & \text { N/A } & 1.05(0.94-1.17) & 1.07(0.96-1.20) & 1.08(0.97-1.21) \\ \mathrm{PM}_{10} \text { and winter } & \text { N/A } & 1.06(0.96-1.18) & 1.09(0.96-1.22) & 1.02(0.88-1.19)\end{array}$

$\mathrm{PM}_{10}$ and temperature interaction:

$\begin{array}{lllcc}\mathrm{PM}_{10} \text { and mod. temp. } & \text { N/A } & \text { N/A } & 1 \text { (ref) } & 1 \text { (ref) } \\ \mathrm{PM}_{10} \text { and cold temp. } & & \text { N/A } & 1.00(0.91-1.09) & 0.99(0.90-1.08) \\ \mathrm{PM}_{10} \text { and hot temp. } & \text { N/A } & \text { N/A } & 1.23(1.00-1.51) & 1.24(1.00-1.52)\end{array}$

$\mathrm{PM}_{10}$ and flu incidence interaction:

$\begin{array}{lllll}\mathrm{PM}_{10} \text { and no flu } & \text { N/A } & \text { N/A } & \text { N/A } & 1 \text { (ref) } \\ \mathrm{PM}_{10} \text { and low flu } & \text { N/A } & \text { N/A } & \text { N/A } & 1.10(0.96-1.26) \\ \mathrm{PM}_{10} \text { and medium flu } & & & \text { N/A } & 1.08(0.92-1.26) \\ \mathrm{PM}_{10} \text { and high flu } & \text { N/A } & \text { N/A } & \text { N/A } & 1.34(0.84-2.15)\end{array}$

\begin{tabular}{|c|c|c|c|c|c|}
\hline Lag 0-2 & $\mathrm{PM}_{10}$ & $1.03(0.90 .1 .18)$ & $0.90(0.76-1.06)$ & $0.87(0.73-1.03)$ & $0.87(0.73-1.03)$ \\
\hline
\end{tabular}

$\mathrm{PM}_{10}$ and season interaction:

$\begin{array}{llccc}\mathrm{PM}_{10} \text { and spring } & \text { N/A } & 1 \text { (ref) } & 1 \text { (ref) } & 1 \text { (ref) } \\ \mathrm{PM}_{10} \text { and summer } & \text { N/A } & 1.14(0.93-1.41) & 1.04(0.83-1.30) & 1.04(0.83-1.30) \\ \mathrm{PM}_{10} \text { and autumn } & \text { N/A } & 1.17(1.04-1.33) & 1.21(1.06-1.37) & 1.21(1.06-1.38) \\ \mathrm{PM}_{10} \text { and winter } & \text { N/A } & 1.16(1.03-1.31) & 1.18(1.03-1.36) & 1.16(0.98-1.38)\end{array}$

$\mathrm{PM}_{10}$ and temperature interaction:

$\begin{array}{lllcc}\mathrm{PM}_{10} \text { and mod. temp. } & \text { N/A } & \text { N/A } & 1 \text { (ref) } & 1 \text { (ref) } \\ \mathrm{PM}_{10} \text { and cold temp. } & \text { N/A } & \text { N/A } & 1.01(0.92-1.12) & 1.00(0.89-1.11) \\ \mathrm{PM}_{10} \text { and hot temp. } & \text { N/A } & \text { N/A } & 1.34(1.05-1.71) & 1.34(1.05-1.71)\end{array}$

$\mathrm{PM}_{10}$ and flu incidence interaction:

\begin{tabular}{lllll}
$\mathrm{PM}_{10}$ and no flu & N/A & N/A & N/A & 1 (ref) \\
\hline $\mathrm{PM}_{10}$ and low flu & N/A & N/A & N/A & $1.01(0.86-1.18)$ \\
\hline $\mathrm{PM}_{10}$ and medium flu & N/A & N/A & N/A & $1.04(0.87-1.25)$ \\
\hline $\mathrm{PM}_{10}$ and high flu & N/A & N/A & N/A & $2.34(1.01-5.43)$ \\
\hline
\end{tabular}

N/A = not applicable 